\title{
Menstrual abnormalities amongst female South African Hajj pilgrims: a cross-sectional study
}

\author{
S Parkera, S Omarb and OH Mahomedc* \\ a South African Society of Travel Medicine (SASTM), Johannesburg, South Africa \\ 'Intensive Care Unit, Chris Hani Baragwanath Academic Hospital, University of Witwatersrand, Johannesburg, South Africa \\ 'Discipline of Public Health Medicine, University of KwaZulu-Natal, Durban, South Africa \\ *Corresponding author, email: mahomedo@ukzn.ac.za
}

Introduction: Hajj (pilgrimage), the fifth pillar of Islam, is obligatory for every Muslim, male or female, provided that he/she is physically and financially able to do so, at least once in his/her lifetime. One of the rituals of Hajj requires the absence of menstruation. In the current modern era, many females utilise oral contraception to manipulate their menstrual cycle so that the pilgrim can be menses free during the main rituals of Hajj. However, many such females are at risk of breakthrough bleeding. Very little information has been documented concerning the incidence of menstrual cycle abnormalities amongst female Hajj pilgrims in general and South African pilgrims in particular. This study aims to determine the incidence of menstrual cycle abnormalities amongst South African female Hajj pilgrims and the potential factors that predispose to them.

Methods: A cross-sectional descriptive study was conducted amongst South African female pilgrims during the five-day Hajj period. South Africa is usually limited to 5000 pilgrims annually with a 50:50 gender split. For most of the five days of Hajj, pilgrims, separated by gender, are housed in special tents. Data were collected using an anonymous self-administered questionnaire. The questionnaires were distributed amongst the ladies' tents in Mina on the last day of Hajj by nursing sisters attached to the South African medical mission. A total of 470 South African female pilgrims participated in the study with 147 excluded as they were either postmenopausal or had had hysterectomies, resulting in a sample size of 323.

Results: Of the 318 participants who responded to the question about hormonal menstrual manipulation (HMM), 195 (61\%) attempted this and $123(39 \%)$ did not. Of the 308 participants who responded to the question concerning menstrual cycle problems (MCP), 54 (18\%) had problems and 254 (82\%) did not. Of the 189 participants who attempted HMM and answered the question on MCP, 44/189 (23\%) had MCP, whilst 10/108 (9\%) of those who did not attempt HMM had MCP. The OR for MCP was 2.97 (Cl 1.46-6.04) if HMM was attempted compared with no HMM attempt.

Conclusion: Menstrual irregularities occurred more frequently in those who attempt hormonal menstrual manipulation compared with those who do not. Health education on this issue should be integrated into the pre-Hajj classes.

Keywords: Hajj, menstrual abnormalities

\section{Introduction}

Hajj, the fifth pillar of Islam, is the oldest and largest annual global mass gathering. ${ }^{1}$ The total number of pilgrims over the last decade ranged between 1862909 in 2016 (the lowest) to a peak of 3161573 in 2012. ${ }^{2}$ Approximately 40\% of the global pilgrims are female.

Hajj (pilgrimage) is obligatory for every Muslim, male or female, provided that he/she is physically and financially able to do so, at least once in his/her lifetime and is undertaken over five days during 8-12 Dhul Hijjah, the 12th month of the Islamic calendar. ${ }^{3}$ Prerequisites for performing the Hajj are to be a Muslim, to be free, to be an adult or mature enough, to be of sound mind, to be able to afford the journey and to maintain one's dependents back home for the duration of the pilgrimage. Pilgrims starts arriving in Makkah 3-4 weeks before the beginning of the Hajj rituals. The ritual rights for men and women are essentially the same. However, for women there are certain rituals that are not permitted whilst menstruating.

Menstruating pilgrims are exempted from the five daily prayers and are not permitted to enter mosques, including the Grand Mosque in Mecca where the Kabaa, the cubic structure which is the direction that all Muslims pray towards, is situated. Menstruating women are also not permitted to read the Quran according to the majority of Islamic jurists. Affected women often feel deprived of their religious activities as the vast majority perform Hajj only once in their lifetime and want to engage in religious activities as much as possible, some of which, whilst menstruating, they are not permitted to partake in. Only one of the rituals of Hajj itself requires the absence of menstruation, despite some misconceptions. This is the Tawaaf, the seven circumambulations of the Kabaa. As for the other actions of Hajj, such as saa'ee between al-Safa and al-Marwah, standing at 'Arafah, staying overnight in Muzdalifah and Mina, stoning the jamaraat and other rituals of Hajj and 'Umrah, these are permissible for such females. ${ }^{4}$ The performance of this obligatory fundamental Tawaaf rite of the pilgrimage is a cause of stress and anxiety for many female pilgrims as waiting for the period to cease is frequently not an option due to very tight pre-booked airline schedules and exhaustion from the long period away from home. Some religious scholars allow concessions for its performance during menstruation when departure from Mecca cannot be delayed, though differences of opinion exist.

In the current modern era, many females utilise oral contraception to manipulate the menstrual cycle via hormonal menstrual manipulation (HMM) so that they can be menses free during the main Hajj ritual period. However, many of them are at risk of breakthrough bleeding and menstrual cycle problems (MCP). Some factors that are considered to predispose to MCP when using $\mathrm{HMM}$ are the concurrent usage of oral antibiotics, which 


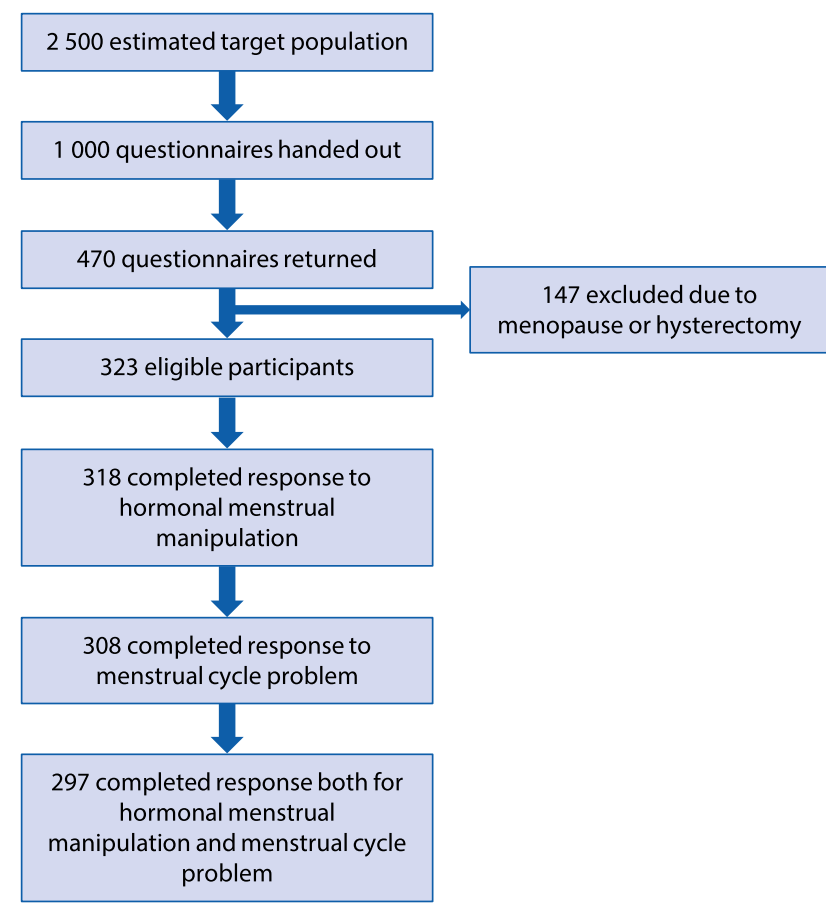

Figure 1: Study population.

are commonly prescribed to pilgrims who present with symptoms of acute respiratory tract infections, commencing HMM very late, or its incorrect usage.

Menstrual irregularities are a common clinical presentation to health facilities globally. As far as their incidence during Hajj is concerned, very little information has been documented. It has been noted in one South African study that 55 of $403(13.6 \%)^{5}$ female consultations were due to MCP. This study aims to determine the incidence of MCP amongst South African female Hajj pilgrims comparing its incidence amongst those who attempted HMM with those who did not attempt HMM.

\section{Methods}

\section{Study design and population}

A cross-sectional descriptive study was conducted amongst South African female pilgrims during the five-day Hajj period. South Africa was limited to 5000 pilgrims annually with an approximately 50:50 gender split each year. For most of the five days of Hajj, pilgrims separated by gender, are housed in special tents.

\section{Data collection}

Data were collected using an anonymous self-administered questionnaire. The questionnaires were distributed amongst the ladies' tents in Mina on the last day of Hajj by nursing sisters attached to the South African medical mission. The participants were briefed by the nursing sister on the content of the questionnaire and were informed that participation was voluntary and anonymous. Participants were assured of confidentiality, anonymity and that the data were to be used in a pooled and not on an individual basis. A self-sealing envelope was provided into which to place the questionnaires, which were then returned to the nurses.

\section{Sampling frame}

The sample size was calculated using Yamane's formula $n=\mathrm{N} / 1+\mathrm{N}(\mathrm{e})^{\wedge} 2$ using a $95 \%$ confidence interval, and a population size of 2500 . A sample size of 334 was required. In order to overcome the logistical challenges and the unavailability of pilgrims 1000 questionnaires were distributed amongst the ladies. A convenience sample was obtained.

\section{Data analysis}

A Microsoft Excel ${ }^{\circledast}$ (Microsoft Corp, Redmond, WA, USA) database was created for data entry. The data were then imported into STATA $10^{\circledR}$ (StataCorp, College Station, TX, USA) for analysis. Data were entered directly into the database using a separate coding sheet so as to minimise the introduction of data-handling errors. All data entries into the database were double-checked against the questionnaires for correctness. The completed database was then examined for inconsistencies and outliers. The computer database was password protected and back-up copies were securely stored. Descriptive statistical analysis was conducted on the data and presented as frequency tables and graphs.

\section{Ethical consideration}

Ethical approval was obtained from the Human Research Ethics Committee (Medical) at the University of Witwatersrand (M092110). Informed consent was obtained from the pilgrims prior to the study.

\section{Results}

\section{Study population}

A total of 470 South African female pilgrims participated in the study (Figure 1). Of this group, 377 answered the question as to whether they would prefer not to menstruate during the journey, with $266(71 \%)$ indicating that they prefer not to and would ideally want to do something about it. In all, 147 participants were excluded from further analysis because they were either postmenopausal or had a hysterectomy. Of the 323 eligible for the study 318 responded to the section on HMM and 308 responded to the section on MCP. Overall there were 297 participants who completed a response to both the HMM and MCP sections.

The mean age of the study population was 33 years (SD: 9). At least $79 \%$ of the study population performing the Hajj were at risk for menstruation as they were between the ages of 13 and 40 years. There was an almost equal distribution $(119,37 \%$ and $124,38 \%$ respectively) of study population in the $21-30$ and 31-40 year age groups (Table 1). The geographic origin of the study shows that $90 \%$ of the participants originated from three provinces in South Africa. These are Gauteng, Western Cape and KwaZulu-Natal. The majority of the study population were from Gauteng (140; 41\%) followed by Western Cape $(98 ; 29 \%)$ and KwaZulu-Natal $(68 ; 20 \%)$. Some $6 \%$ (19) of the study population were using oral contraceptives for family planning purposes; 87 participants (27\%) of the study population received a concomitant course of antibiotics during their visit (see Table 1).

\section{Menstrual manipulation}

There were 318 respondents who completed the HMM section of the questionnaire. Of these, 195 (61\%) attempted HMM while 123 (39\%) did not. A combination low-dose oral contraceptive pill was used by 146 participants ( $46 \%$ of all respondents, $75 \%$ of those attempting HMM) and a progesterone-only pill by 50 participants ( $16 \%$ of all respondents, $25 \%$ of those attempting HMM). Family planning was cited as an additional reason for oral contraceptive use among 19 (6\%) participants. 
Table 1: Frequency table of the profile of the study population

\begin{tabular}{lcc}
\hline Item & Number & Percentage (\%) \\
\hline Age distribution: & 16 & 5 \\
$13-20$ & 119 & 37 \\
$21-30$ & 124 & 38 \\
\hline $31-40$ & 56 & 17 \\
\hline $41-50$ & 8 & 2 \\
\hline $51-60$ & & \\
\hline Provincial profile: & 132 & 41 \\
\hline Gauteng & 65 & 20 \\
\hline KwaZulu-Natal & 90 & 28 \\
\hline Western Cape & 31 & 10 \\
\hline Other & 5 & 2 \\
\hline Missing & 87 & 27 \\
\hline Received antibiotics during stay in holy & & 6 \\
\hline sites & 19 & \\
\hline On contraceptives for family planning & & \\
\hline
\end{tabular}

\section{Menstrual cycle irregularities during Hajj (MCP)}

There were 308 respondents who completed the MCP section of the questionnaire. Of these $54(18 \%)$ indicated that they had MCP during their pilgrimage whilst 253 (82\%) experienced no MCP.

\section{Menstrual manipulation and MCP}

A total of 297 respondents completed both the HMM and the MCP sections. A total of 54 (18\%) reported MCP while 243 (82\%) reported no MCP. The absolute risk of bleeding in those who attempted HMM was $23 \%$ (44/189), while it was $9 \%(10 / 108)$ in those who did not attempt HMM. There was a significantly greater risk of MCP for those attempting $\mathrm{HMM}$, with an odds ratio of 2.97 (1.46-6.04).

\section{Discussion}

Menstrual irregularities and breakthrough bleeding are a source of anxiety for female pilgrims attending the Hajj pilgrimage due to the restrictions imposed on their performance of religious obligations. ${ }^{6}$ The relatively young age of the pilgrims in the study group (37\% were between 21 and 30 years) could make them more susceptible to MCP during the Hajj period. The anxiety and inconveniences associated with menstrual irregularities during the Hajj period comprise a major factor that influences pilgrims. This is only the second study to date that we are aware of addressing hormonal manipulation for the avoidance of menstrual irregularities during the Hajj pilgrimage.

The results from the current study indicated that $61 \%$ of the surveyed pilgrims attempted to manipulate their monthly menstrual cycle, with $82 \%$ of the participants successfully preventing menstruation. Although the proportion of pilgrims who reported using contraceptive agents to prevent bleeding is less than those reported in an Iranian study (99\%), the outcome of preventing menstruation in the current study is slightly higher (82\% versus $75 \%)^{7}$

In the current study, like the global preference, the majority of the female pilgrims utilised oral contraceptive pills to prevent menstruation. One Nigerian study, ${ }^{8}$ however, showed that despite a high level of awareness of HMM, there was low utilisation of menstrual suppression among Nigerian female pilgrims.
Despite taking pills, 44/189 (23\%) of the pilgrims participating in the current study experienced menstrual irregularities in comparison with the Iranian study, which reported spotting in $26 \%$ and menstruation in $12 \%$. Our data suggest that more patients on combined low-dose oral contraceptive pills experienced menstrual abnormalities when compared with patients on progesterone-only pills. However, further studies are needed to evaluate this, as the numbers involved were low and some women first used a combined oral contraceptive and, when they had problems, switched to progesterone only. Not much is known about the efficacy of this practice. A further factor that was not asked about but should have been considered is that many of the pilgrims not on any contraception may have commenced the combined oral contraceptive pill four weeks prior to the pilgrimage, or may have switched to oral contraceptives from other modalities. A high prevalence of side effects has been reported in women who used contraceptive pills for the first time. Additionally, previous studies have reported a high and variable prevalence of spotting and bleeding when extended and continuous regimens for preventing menstruation are utilised. However, these unwanted side effects were eliminated after a few cycles. ${ }^{9}$

Another factor to consider is the high proportion of women treated with antibiotics (27\%). The role of an antibiotic drug interaction as a cause of MCP also needs evaluation. ${ }^{10}$ This is important as appropriate antibiotic utilisation and antibiotic stewardship is a topic of great interest currently. ${ }^{11}$ Furthermore, if antibiotic use is associated with MCP, then this may be a modifiable risk factor.

There were a number of limitation to the study. We did not ascertain whether some women had regular cycles and whether their menses would have occurred outside the Hajj period and hence they decided not to use HMM. Some women attended for only two weeks and may have known that they would be menstruation free, making HMM unnecessary. Late commencement of HMM, as indicated above, may have affected the results. Poor compliance due to moving from one place to another during the Hajj was not investigated but is known to predispose to intermenstrual bleeding or unexpected per vagina bleeding while on HMM.

The findings of the above study, although limited by the crosssectional study design and the presence of social desirability bias, which could have been introduced as the pilgrims share a common air-conditioned tent during the five days of Haj, have important health-promotion implications for prospective female Hajj pilgrims. Most prospective pilgrims are informed between three and six months prior to their departure for Saudi Arabia of their accreditation to perform the pilgrimage. A number of predeparture orientation sessions are conducted in the various provinces under the guidance of religious scholars. The key focus is on the psychological preparation of the pilgrim on this epic journey. From a medical perspective, the medical practitioners provide information on the necessary vaccinations for the visa application, precautions against the acquisition of infections, especially respiratory tract infections, food hygiene and medical service availability during the pilgrimage and stay in Saudi Arabia. Due to the personal nature of female gynaecological conditions, very little emphasis is placed on menstrual irregularities. The onus is left on the female pilgrimage to consult with her health professional to address any concerns that may arise. 
This study shows that, like the Iranian investigations, the majority of South African female Hajj pilgrims prefer not to menstruate during the Hajj period and attempt HMM. Factors such as early commencement of HMM, selecting the most appropriate contraceptive pill based on the risk profile of the pilgrim, the importance of adherence, potential drug interactions, side effects and instructions on how to cope with side effects such as spotting should be addressed. It is proposed that this topic should be raised in the Hajj awareness classes run by the South African Hajj authorities and travel agent groups. Since the majority of pilgrims reside in the three main centres (Gauteng, Western Cape, KwaZulu-Natal) where the Hajj authorities have offices, it should be relatively easy to disseminate this information.

\section{Conclusion}

Menstrual irregularities during the Hajj pilgrimage are a source of great anxiety, stress and inconvenience. The incidence of MCP was higher in pilgrims attempting $\mathrm{MHH}$ compared with those who did not attempt it in the current study. South African female Hajj pilgrims prefer not to menstruate during the Hajj and attempt HMM. We have found that this practice is associated with a greater risk of MCP compared with not using HMM. Health education specifically focusing on menstrual manipulation should be integrated into the pre-Hajj classes.

Disclosure statement - No potential conflict of interest was reported by the authors.

\section{References}

1. Shujaa A, Alhamid S. Health response to Hajj mass gathering from emergency perspective, narrative review. Turk J Emerg Med. 2015;15:172-6. https://doi.org/10.1016/j.tjem.2015.02.001

2. General Authority of Statistics. Hajj statistics 1437. Riyadh: General Authority of Statistics; 2016.

3. Kraemer JL, Peters FE. The Hajj: The Muslim pilgrimage to Mecca and the Holy Places, and Mecca: A literary history of the Muslim Holy Land. Hist Relig. 2000;40:198-203. https://doi.org/10.1086/463631

4. Elias, AH. Haiz During Hajj. Durban: Alislam; June 2017. Available from: http://www.alislam.co.za/qna/haiz-during-hajj/1.

5. Parker S. The Hajj: A constant travel destination amidst changing times. South Afr J Epidemiol Infect 2010;25(1):14-18.

6. RiazSA, Ahmadi M, Mortazavi SM. Predictors of anxiety and depression among women with vaginal bleeding referred to gynecology clinic during hajj 2011. Iran Red Crescent Med J. 2014;16:e12855.

7. Dandehbor W, Kazemi M, Salehi Shahrbabaki MS, et al. Menstrual suppression using oral contraceptives by Female Hajj Pilgrim. Int J Travel Med Global Health 2016;4:111-114. https://doi.org/10.21859/ ijtmgh-040405

8. Mohammed-Durosinlorun A, Raji HO, Hussain NA, et al. Menstrual suppression among female Nigerian pilgrims during Hajj. J Fam Plann Reprod Health Care 2012;38:270-71.

9. Mansour D. Experiences with Yasmin; the acceptability of a novel oral contraceptive and its effect on well being. Eur J Contracept Reprod Health Care 2002;7:35-41.

10. DeRossi SS, Hersh EV. Antibiotics and oral contraceptives. Dent Clin North Am 2002;46:653-64. https://doi.org/10.1016/S0011-8532(02) 00017-4

11. Martin CM. Antibiotic stewardship: New frontier. Cons Pharm. 2017;32:27-32. https://doi.org/10.4140/TCP.n.2017.134 